TItLE. A STATISTICAL THEORY OF FRAGMENTATION PROCESSES

$$
\text { Isi:-Ui:- - } 4-3173
$$

AuTmOn(s) John K. Dienes

$$
\text { DLST: 00.206 }
$$

susmitred to Workshop on Enelastic Deformation and Faflure Modes November 18-21, 1984

Allen Center, Northwestern Unlversity

Eranston, IL

Proceedings to be published 1r. Mechanica of Materials

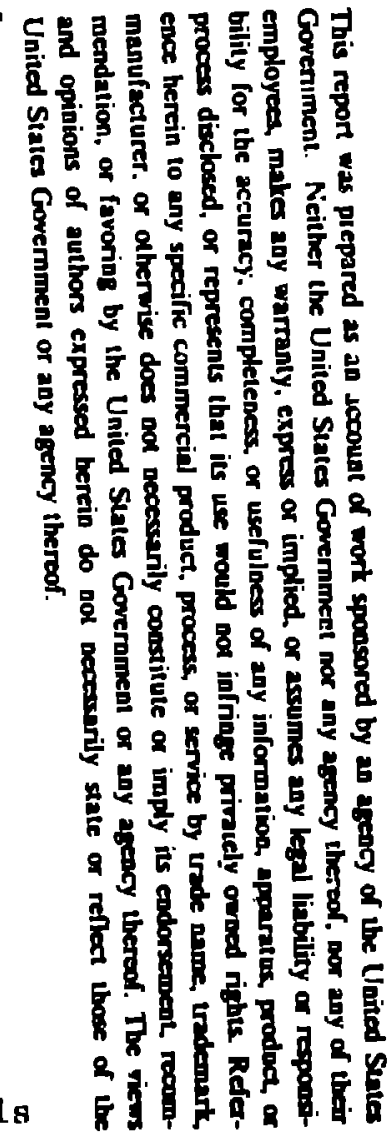




\section{A STATISTICAL THEORY OF FRAGMENTATION PROCESSES}

John K. Dienes

Theoretical Division

Los Alamos National Laboratory

Los Alamos, NM 87545 USA

The goal of the work reviewed here is a theory of material behavlor accounting for the average deformation that regults from the openIng, shear, growth and coalescence of an ensemble of microcracks. A concomitant is the calculation of permeabllity from crack atructure. The first part of this paper simmarizes prevlous deveinpments. In particular, the Inttial work on this problem made use of a linear Llouville equation to characterize the change In crack distribution reBulting from crack growth and conlescence. Stralghtforward analytic onlutions to this equation were possible because the mean free path of cracks was assumed constant. Though thls assumption is useful for the early atages of crack srowth, Increasing crack alze reduces the mean free path in the later stages of fragmentation. This problem la addressea in ihe gecond part of thls paper. The governing (nonlinear) Louville equation Ia derlved thereln, and it is ahown thint 1 t can be reduced to an ordinacy differentlal equntion of third order Involving only a stagle parameter, $\beta$. Thls equnt ton lias now beun solved numertsally to determine the $11 \mathrm{mLt} / \mathrm{ng}$ value of the mean free path ae a function of $\beta$, and the results are prosonted in graphical foria. In tho thlid part of this paper prospecta for further developmenta nre briefly Hlachsaed. 
A STATISTICAL THEORY OF FRAGMENTAIION PROCESSES 
1. Reylew of Previous Work

One of the assumptions that has made it possible to formulate constitutive relations accounting for the behsvior of fragaenting oolids is that the strain rate can be represented as the sum of contributions from disparate physical procesges. This assumption can be consldered a generallation uf Reuss' (1930) concept of separating the strain rate Into a sum of elastic and plastic parts. Phystcally, one can envisage the total gtrain in a plasttcally deforming oolid as the sum of the elastic otraln in a soltd lattice which is determined by the prescribed stress usting lineaz elasticity, and of nonlinear slip along planes of weakness, represented by a phenomonological plasticlty law. The superpositinn can be represented in a number of ways, depending, on the variables selected. The most natural for computationul purposes is to work with the streiching $D$, which la defined by aeparating the veloctty gradient $G-\left(u_{1, f}\right)$ into the sum of a symmetric part $D$, the stretching, and an antiaymmetrlc part $W$, the vortlclty, so that

$$
G=D+W
$$

The atretching can be related to the strain

$$
E=\frac{1}{2}\left(B^{2}-I\right)
$$

where

$$
B=\mathbf{F F}^{\mathrm{T}}
$$

In the loft Cauchy-creen tunaor and $F$ is the deformation gradtent, by 


$$
\hat{\mathbf{E}}=\mathrm{VDV} \text {. }
$$

Here the circumflex denotes the material rate discussed by Dienes (1979a) and the left stretci $V$ it defined by

$$
v^{2}-B
$$

The above definition of gtrain differs from those usually adopted, but is thought to be the most useful. Spr:iflcally, the otrain rate defincd above 1s the actual rate of change (accounting for rotaticn) of strain. (Tile stretching $D$, of ten taken as the strain rate, is not the rate of any history-independent varlable.) The aummation principle can be applied to cithe: $\hat{E}$ or $D$, with equivalent results according to $(1.4)$, but the application in terms of $D$ is more convenient for computational purposes. Contributions to the stretching in a fragmenting material can arise from elastic changes in the lattice etructure, $D^{e}$; frum thc motion of $\theta 11 p$ planes and dislocetlons that cuntribute to plastic flow, $D^{P}$; from crack opening $D^{0}$; from shearing of closed cracks $D^{B}$; frum unstable gruwth of elther open or closed cracks, $\eta^{\mathrm{g}}$; from nonlinea: Interatomic and chermal effecta represented by an 18otropir. equation of 13 tate, $D^{n}$; and from viscous behavlor, Dv. Thus, one may write

$$
D=D^{e}+D^{p}+D^{0}+D^{B}+D^{\phi}+D^{\prime \prime}+D^{v} .
$$

Since the rate at which work 18 done by the atrese o is the trace uf ob, each term of $(1.6)$ is asgorlated with the energetica of a purticular deformation mechaniem. The elastic term can be wrltten, in Indicial nistation, as

$$
D_{1 j}^{e}=\dot{S}_{1 . j k \ell} \hat{\sigma}_{k \ell}
$$


where $\mathrm{C}$ is the compliance and $\hat{\sigma}$ ts the stress rate defined by Dienes (1979a).

To account for plastic behavior in general deformation it is necessary to allow for arbitrary states of stress and, consequently, to make use of a hardening plasticity theory. An approach to this problem has been recently developed using kinematic hardening theory (Dienes, 1984a,b) but detalls are omitted here since space does not allow a complete discussion, and the main purpose of this paper is to review the work on statistical crack mechanics. As cracks open, a certain amount of material lo jisplaced, If it is assumed that the surrounding matertal does not change 1to density, and that the rate of materlal displacement in each direction 18 the sum of displacements due to the Individual cracks, then 1 t has been shown by Dtenes et al (1980, 1983a) that the strain rate Induced by an ensemble of penny-shaped cracks lo

$d_{1 j}^{o}=\beta^{o} z_{1 j k \ell k \ell}^{0}$

where $\beta^{\circ}$ is a material constant and

$$
z_{1 j k l}^{0}=\int_{0} d O n_{1} n_{j} n_{k} n_{l} \int_{0}^{\infty} d c\left(-\frac{\partial n^{0}}{\partial c}-\right) c^{3}
$$

llere $n^{\circ}(c, Q, t)$ denotes the number density of open cracks with orientation 0 whose radil exceed $c$, and $n_{1}$ denotes the lth component of a crack normal. Cracks are conaldered open when the normal component of traction

$$
\bar{\sigma}=\sigma_{1, j} n_{1} n_{j}
$$

It poritive (tenglle). 
In addition to the stretching associated with crack opening, there can be a contribution resulting from the interfaclal silding of closed cracks, for which the normal component of traction is negative (compressive). The assoclated stretching is

$$
d_{1 j}^{g}=\beta^{s} z_{1 j k \ell}^{s} \hat{\sigma}_{k l}
$$

where $\beta^{9}$ is another material conistant and

$$
z_{1 j k l}^{B}=\int_{0} d Q(1-a) b_{1 j k l} \int_{0}^{\infty} d r\left(-\frac{\partial n^{8}}{\partial c}\right) c^{3} .
$$

The quantity $\alpha$, arising froin the effect of interfacial friction between closed cracks, is given by

$$
\alpha-\bar{\mu}|\tilde{\sigma}|\left(A-\tilde{\sigma}^{2}\right)^{-\frac{1}{2}}
$$

where $\bar{\mu}$ ig the coefficient of friction and $\Lambda$ represents the magnttude squared of tracticin:

$$
\Lambda-\sigma_{1 j} n_{j} \sigma_{1 k} n_{k}
$$

Only the digtribution of closed cracks $n^{8}(c, Q, t)$ enters into this calculation, and thelr effect is to modify only the shear otrain, and not the dtlatation. Thus, the operator

$$
b_{1 j k l}-\delta_{1 \ell} n_{j} n_{k}+\delta_{j l} n_{1} n_{k}-2 n_{1} n_{j} n_{k} n_{l}
$$

defined in the process of deriving (1.12), has a property such that . 11 valllshes, enforcing the sheat constralnt mentloned above. If a exceeds unlty, the normal stress is great enough to lock cracks with the correspondling ori- 
entation, and their contribution to (1.12) is made to vanish in detailed calculations. Th1s introduces the hysteretic effect of solid friction.

If the stress is high enough so that cracks are unstable, they grow at a rate which can approach half the wave speed, but the rate may be much lower at modest stress levels. The strain rate due to crack growth is given by

$$
d_{1.1}^{R}=\left(\beta^{0} z_{1 . j k \ell}^{0}+\beta^{s} \dot{z}_{1 . j k l}^{s}\right) a_{k \ell}
$$

where the dots Indicate that in (1.9) and (1.12), $n^{0}$ and $n^{8}$ are to be replaced by their time derivatives. The criterla for crach instahility are discussed in a separate paragraph below.

At high pressure, when the state of stress is nearly 1sotroplc, material behavtor is dominated by san isotropic equation of state relating presourd $n$, to the density $p$ and internal energy $I$, of the form (Mcqueen et al, 1970)

$$
p=G(p) \rho I+f(p)
$$

It is conventent and reasonably accurate for many materlals to take $G_{p}$ as a constant, Gop, nnd to assume a linear relation

$$
u_{B}=c_{0}+s u_{p}
$$

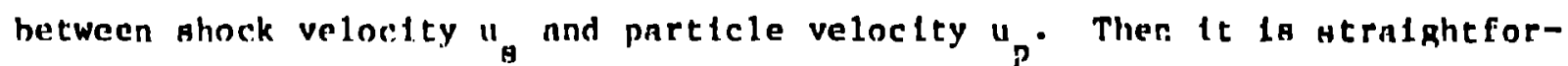
ward to show that

$$
f(n)=\frac{: \theta\left(1-\sigma_{0} \theta / 2\right)}{(1-s 0)^{2}}
$$


where $k$ denotes the bulk modulus, equal to $\rho_{0} c_{0}^{2}$, and $\theta$ denotes the compression

$$
\theta-1-\rho_{0} / \rho
$$

Only the nonlinear part of the equation of state (1.17) is incorporated into the term denoted by $D^{n}$ or $(1.6)$.

The overall compliance of the fractured material $\mathrm{C}$ can be represented as the sum

$$
C-c^{e}+\beta^{o} z^{o}+\beta^{\beta} z^{s}
$$

It is conventent for specific calculations to write

$D_{I}^{e l}-C_{I J} \sum_{\sim}^{0 J}$

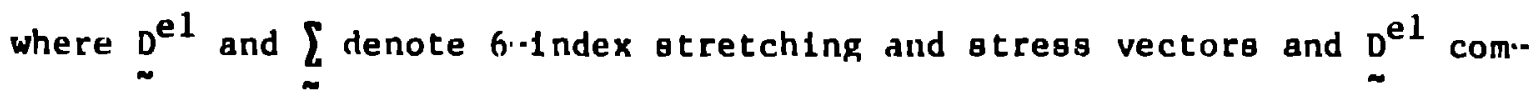
bines the stretching due to lattice otrain, crark opening and crack shear1ng. Then (1.6) can be solved for the stress Increment

$$
\Delta \sum-C^{-1}\left(\underline{D}-\underline{D}^{p}-\underline{D}^{n}-\underline{D}^{g}-\underline{D}^{v}-\underline{D}^{\mathrm{r}}\right) \Delta t
$$

This formula includes $\mathrm{\sim}^{\mathrm{r}}$, an effective strain rate that arises from the calculation of otress rate, In addition to terme previously described.

When the far-field stregs on a crack exceeds a critical value, a mechanlcal Instablilty is induced and cracks begin to grow. This instability occurs when the work done by external tractions as a result of an increment In crack size exceedu the Increase in internal energy. Thio Internal energy 
1s the sum of an elastlc otraln energy, surface energy and, for closed cracks, heating due to frictional sliding. For penny-shaped cracks in tension the strain energy is the sum of the tensile contribution determined by Sack (1946) and a shear contribution found by Segedin (1950) and Is given by

$$
W_{0}=\frac{4}{3} \frac{c^{3}}{\mu}-\frac{1-v}{2-v}\left(2 A-v \bar{\sigma}^{2}\right)
$$

as shown ty Keer (1966). Here $v$ denotes the Polsson ratio, p the shear modules and $c, A$, and $\vec{\sigma}$ are def 1 ned above. Then $1 t$ can be shown that ope' 1 cracks are unstable if

$$
A<v \tilde{\sigma}^{2} / 2+\pi \gamma \mu(2-v) / 2(1-v) c \text {, }
$$

where $\gamma$ denotes the specific surface energy. If plastic effects contribute slgnificantly, then $\gamma$ can be increased to account for enhanced toughness in an approximate way. For closed cracks, only the strain energy assoclated with shear is involved. This can be written

$$
w_{s}=\frac{8}{3 \mu} \frac{1-v}{2-v}(\sigma-\tau)^{2} c^{3},
$$

where $\sigma$ and $\tau$ denote the tangential components of traction associated with the far-field stress and luterfacial friction. A proof that otraln energy depends or utress difference in this manner, with

$$
\sigma=\sqrt{\Lambda-\tilde{\sigma}^{2}}, \tau=-\bar{\mu} \tilde{\sigma}
$$


Io given by Dlenes (1983b). Rice (1984) corrects the stabllity criterion derived by Dienes and shows that an instability occurs if

$$
(\sigma-\tau)^{2} c>\frac{\pi}{2} \frac{2-v}{1-v} \gamma \mu
$$

The growth and coalescence of iracks is charactertzed by two diutribution functions. The distribution of 1solated cracks is characterized by $\ell(c, Q, t)$, the number of 1solated, penny-shaped cracks per unit volume with ortentation $\Omega$ at time $t$ whose radil exceed $c$. The distribution of connected cracks is given by a corresponding function $m(c, \Omega, t)$. The sum of these distributions is $n(c, \Omega, t)$. It la shown by Dienes (1978) that these distributions are related by a Llouville equation

$$
\ell_{c} \dot{c}+\dot{\ell}=-\dot{m} .
$$

At early times, while the inean free path is essentialif constant,

$$
\dot{m}=k \ell
$$

where $\mathrm{k}$ is a constant related to the mean free path. The linear equation obtained by conolning $(1.29)$ and (1.30) is readily solvable when the infital distribution is exponential in crack size, with the result

$$
\ell=\ell_{0} e^{-c / \bar{c}+(\dot{c} / c-k) t}
$$

valld for $c \geq \dot{c t}$; otherwise, $l$ vanishes. Th1s solution call represent anlsotroptc materials euch as ofl shale, since $l_{0}, \bar{c}$ and $k$ can depend on orfentation. Results showing new classes of phewomena appearing tn an anisotrople 
material have been described by Dienes $(1979 \mathrm{~h}, 1981)$. The assumption of constant $k$ may not be useful when the total crack area 1ricreases significantly as the result of growth. Th1s is the subject of the second part of this paper.

The permeability tensor for fractured materials has been computed by Dienes (1982) as

$$
K_{j k}=\frac{64}{45} \theta \int d^{3}{ }^{3}(\Omega) r_{1 k} G(\Omega)
$$

Here $\theta$ denotes a crack shape factor near unity, A is the aspect ratio of the cracks,

$$
r_{1 k}=\delta_{1 k}-n_{1} n_{k}
$$

and

$$
G(\Omega)=-\int d c \frac{\partial m}{\partial c} c^{5}
$$

ts the fifth moment of crack radius. If the cracks are lootroplcally distributed

$$
K_{11}=\frac{8 \pi^{2}}{15}-\theta \Lambda^{3} n_{0}\left\langle c^{5}\right\rangle
$$

and the tensor is diagonal and 1sotroplc. The complete theory accounts for the probahiltty of crack intersectins and their coalescence into cunnected paths, and 1s discussed in the derivation. It also accounts for the posg1bility that there are not enough cracks to form connected paths by using percolation theory, not discussed herein. 


\section{Varlable Jean Free Paih}

Consider a homogeneous, Lsotroplc medium filled with clrcular cracks that are randomly, homogeneougly, and 1sotroplcally distributed. If aubJected to a stress field of suffjcient intensity, cracks in a real material are unstable, and their growth can cause important changes in the macroscoplc propnrties of the medium. This behavior is complicated by crack intersections, whose frequency is governer. by the area per unft volume of cracks, a quantty that changes as the cracks 1ncrease in size. Thus, the mean free path of crarks is much more difficult to deal with than the mean free path o jases, which remalns colstant. The current approach 1dea11zes material behavior by dividing the cracks into just two categories, those that ar? eseentially loolated and those that have intersected a number, $\alpha$, of other cracks and, as a reunlt, are no longer capable of growth. The 18olated cracks are considered cctive, that is, capable of unstable growth if the otress level exceeds a citical value, whereas the other cracics are corisidered Inactlve, and will not exhihit growth even at high stregs levelg because the1r edges have Intersected the planes of other cracks, and there 1a no longer a regiun of atress concentration or an excess of atrain energy to drive crack growth. This is of courge, a great 1dealization, and the reader w11l quiskly be able to demonstrate a number of geometrtc and physicnl effecta which this Idealization fallo to nccount for. St111, even this relatively simple approach leadu to considerable mathematical complexity. The consequences of this appronch are examlned in some detati here. The gont is to obtaln an approximate, alhelt crude, treatment nf crack coulescence thut Lo Ugable In real calculutions of pormenblllty, fruginentation and reinted effects. In addltion, te Ia posathle that the conclusiona may nuprest promIsing approximations. 
The number density of 1solated (active) cracks per unit volume whose radi1 exceed $c$ is denoted by $L(c, t)$, and the number density of connected (inactive) cracks per unt volume whose radil exceed c 18 denoted by $M(c, t)$, where $t$ denotes the duration of crack growth. The number of active cracks at $t$ ime $t+\Delta t$ larger than $c$ is equal to tha number at time $t$ larger than c. $\dot{c} \Delta t$, less the number that have been converted Into Inactive otatus, $M_{t} \Delta t, 1 ;$ the Interval $\Delta t$. Here $\dot{c}$ denotes the gpeed of crack growth, agsumed unifnrm around the crack edges, but not necessarily constant in time. Subocripts cienote differentiation. Symbolicaliy,

$$
L(c, t+\Delta t)-L(c-\dot{c} \Delta t, t)-:_{t}(c, t) \Delta t
$$

or, passing to the $11 \mathrm{mlt}$ of omall $\Delta t$,

$$
\mathrm{I}_{\mathrm{c}} \dot{\mathrm{c}}+\mathrm{L}_{\mathrm{t}}=-\mathrm{M}_{\mathrm{t}}
$$

The veiocity dependence can be eliminated by Introducing a new variable

$$
r=\int_{0}^{t} \dot{c} d t
$$

representing the extent of crack growth. Then the governing equaton oimplifies to

$$
\mathrm{L}_{c}+\mathrm{L}_{\gamma}-\mathrm{M}_{\gamma}
$$


To make further progress it is necessary to characterize the rate of formation of Inactive cracks. To this end, let $L$ denote the length of edges of all the active cracks with radius exceeding $c$, per unit volume. Then, 6ssuming clrcular cracks,

$$
L=\int_{c}^{\infty} 2 \pi !\left(-\frac{\partial L}{\partial c}\right) d c
$$

The area swept out by cracks of radius exceeding $c$ in time $\Delta t$ is $L \dot{c} \Delta t$. Now, let $\eta$ denote the number of crack intercepts per unit nrea on an arhitrary plane, a quantity independent of the plane selected in vlew of the statsitical agaumptions. (Later, it will be important to separate out the concributions from active and Inactive cracks, but that is unnecessary at this point.) The variable $\eta$ depends on $\gamma$, but not on $c$, an Important point in the solution procedure that follows. Now, the rate at which cracks intersect (per unit volume) 1s equa1. to the product of two terms, the rate at which area ts heing owept out hy growing cracks (per unit volume) and the linber of cracks per untt area. The rate at which cracks become innet/ve ta $1 / \alpha$ times the rate at whlch intersections form. Then, using (2.2),

$$
M_{\gamma}=L(c, \gamma) \eta(\gamma) / \alpha
$$

It Is conventent to define

$$
z=L_{c}, k=2 \pi / \alpha
$$

Iu order to oblalin a nimple form for the goveruling equnt lon, which then roduces to 


$$
z_{c}+z_{\gamma}+k c \eta z=0
$$

The solution procedure falls naturally into two parts. In the first, form for the solution involving only a function of one variable, $J(\gamma), 18$ determined. Then, an expression for $\eta(\gamma)$ in terms of $L(\gamma, c)$ is formed, By combining these resulte a third-order ordinary differential equation is obtained whose solution determines. J. The mean free path can then be obtained In terms of $L(\gamma, c)$.
A solution of (2.7) can be obtalned by the transformation
$u=c-\gamma, v=c+\gamma$

which results in

$$
z_{v}+(k / 4)(u+v) \eta\left(\frac{v}{2}\right) z=0
$$

This has the Integral

$$
\eta=h(u) e^{\left.k \mid c J^{\prime}(\gamma)-J(\gamma)\right]}
$$

In terms of the orlginnl vnri,bles, where

$$
J "=-n(\gamma), j(0)-J^{\prime}(0)=11 .
$$

Le fol LOWH that

$$
l,(\gamma, r)=-0^{k\left|\gamma \cdot J^{\prime}(\gamma)-. J(\gamma)\right|} \int_{c-\gamma}^{\infty} d u h(u) e^{k u J^{\prime}(\gamma)}
$$

If $8<y$, the Integrand In (2.12) line to log Het to goro wherover 11 ta negh-

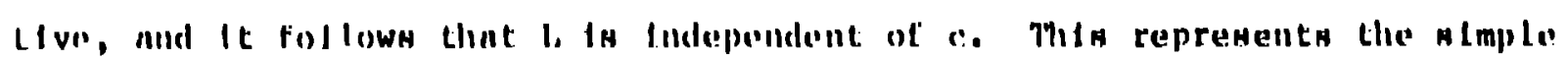


fact that when the growth is $\gamma$, no active crack can have a radius less than Y.

In Appendix A it 18 shown that the number of crack segments per unit area for cracks with a olze distribution $P(c)$ is

$$
\eta_{P}=\frac{\pi}{2} \int_{0}^{\infty} P(c) d c
$$

'l'hen, the number of astive cracks per unit area is

$$
\eta_{a}=\frac{\pi}{2} \int_{\gamma}^{\infty} I_{l}(\gamma, c) d c
$$

A Bimflar relation can be written for the connected (Inactive) cricks, though in this casc te cannot he expected to he very accurate hecause the Intelally clrcilar shape will not be retilned in real materlals nfter lutersection. Thus, when cracks are assuned to be active untll a tritersections have occurred, their gi:owth la somewhat overeatimated. I'hls estimate,

$$
\eta_{1}=\frac{\eta_{i}}{i_{0}} \int_{0}^{\infty} d c M(c)
$$

really representy an upper hound on $\eta_{1}$. The integrntion la carried mit in Append1x B. When the result is comblned with the procedling onc, the totnl number of netlve nnd Innetlve cricke per unlt urea la

$$
\eta=n_{n}+n_{1}-\frac{\pi}{2}\left\{\int_{n}^{\infty} !(0, c) d c+\int_{0}^{\gamma} l_{1}(c, c) d c-\gamma l(\gamma, \gamma)\right\} .
$$

llener, 


$$
\frac{d \eta}{d \gamma}=-\frac{\pi}{2} \frac{d}{d \gamma} L(\gamma, \gamma)
$$

Now, though the theory of Laplace trangforma is not employed here, it is convenient to use itg notation, viz

$$
\bar{h}(s)=\int_{0}^{\infty} e^{-s u} h(u) d u .
$$

Then, from (2.12)

$$
L(\gamma, \gamma)=-e^{-k\left(J-J^{\prime}\right)} \bar{h}(\theta)
$$

where

$$
\text { s }-k J^{\prime}(\gamma) \text {. }
$$

Comblning (2.11), (2.17), and (2.19), we are led to the governing equation

$$
J^{\prime \prime}=\frac{\pi}{2} k \gamma\left(\frac{d \bar{h}}{d A}-\gamma{ }^{\prime} i\right) J " e^{-k\left(. J-\gamma J^{\prime}\right)}
$$

for $J(\gamma)$.

If the cracks hnve nn Infthallv exponentinl distribution, so that

$$
h(c)=-\left(L_{0} / \bar{c}\right) r^{-c / \bar{c}}
$$

then

$$
\pi=-L_{n} /\left(1+\sigma_{H}\right) \text {. }
$$


In this case the gnverning equation becomes

$$
J^{\prime} \cdot+=\frac{\pi k}{2} \gamma L_{0} \frac{\bar{c}+\gamma(1+\overline{\underline{s} \theta})}{(1+\overline{c s})^{2}} J^{\prime} \cdot e^{-k\left(J-\gamma J^{\prime}\right)} \cdot
$$

Th1s can be put into a canonical form by the scaling transformations

$$
w=-k J, \theta-\gamma / \bar{c}, \beta=\pi k \bar{c}^{3} \mathrm{~L}_{0} / 2,
$$

with the regult

$$
W_{\theta \theta \theta}=\beta \theta \frac{1+\theta+\theta W_{\theta}}{\left(1+W_{\theta}\right)^{2}} W_{\theta \theta} e^{W-\theta W_{\theta}} .
$$

Since the Initiul confitions for $W$ are

$$
W_{\theta \theta}=\beta, W=W_{\theta}=0
$$

It foliows that $W$ is a function of $\theta$ with only one parameler, $\beta$. The variation of $W$ with $\theta$ for varioug $\beta$ is tllustrated in Fig. 1.

The mean free path of cracks can be obtained by insidering the profected crack area (on some arbitrary plane) per unit voiume. For all 180tropic distribution the projected area per unit volume it piven by

$$
A=\int_{0}^{\pi / 2} \sin \theta \cos \theta d \theta \int_{0}^{2 \pi} d \int_{0}^{\infty} \pi c^{2}\left(-\frac{\partial n}{\partial c}\right) d c
$$

where $n$ ta the distribution of eracks per $2 \pi$. For en teotrople dithtrbuclon 


$$
A=\pi \int_{0}^{\infty} c N d c
$$

where $\mathrm{N}=2 \pi n 1 \mathrm{~s}$ the density of cracks with all orfentations. If we consider a cylinder of length $S$ and unt crose-sectional area filled with this 1sotropic distribution, the number of intersections that a generator of the cylinder will have with the contalned cracks is AS. The length for which the number of intersections is unity is the mean free path

$$
\lambda=1 ; \mathrm{A} .
$$

For an inftially exponential distribution

$$
\lambda=\lambda_{0}=1 / \pi L_{0} \bar{c}^{2}
$$

To determine the mean free path for the more general case it ls necessary to evaluaice the Integral

$$
\Lambda=\pi \int_{0}^{\infty} c(L+M) d c
$$

where Eq. B.6 ta uged for $c\langle\gamma$ and Eq. B. 5 for $c>\gamma$. In both rases $\bar{\gamma}\langle\gamma$, so Eor an exponential tlatribution the Integrand ts

$$
\left.I_{c}(\gamma, c)=-\left(I_{n} / \bar{c}\right) e^{-k[\cdot J(\gamma)-c J}(\gamma)\right]+(\gamma-c) / \bar{c} .
$$

Por e $<\gamma$

$$
1=\frac{L_{0} 0^{-k\left(J-\gamma J^{\prime}\right)}}{1-k \bar{c} J^{\prime}}
$$


1s Independent of $c$, and for $c>\gamma$

$$
L=\frac{L_{0} e^{-k\left(J-c J^{\prime}\right)+(\gamma-c) / c}}{1-k \bar{c} J^{\prime}} .
$$

W1th these relations it is possible to determine the mean free path as a function of the growth $\gamma$, though it 18 necessary to carry out the Integrations numerically.

The results can be put in dimensionless form by defining the dimensionless mean free path

$$
\mu=\bar{c}^{2} L_{0} \lambda-\left[\int_{0}^{\infty} \theta d \theta(\tilde{l}+\tilde{m})\right]^{-1}
$$

whare

$$
\tilde{\imath}=L_{L} L_{0}, \tilde{m}=M / L_{0}, \theta * c / \bar{c} .
$$

The quantity $\mu 18$ plotted as a function of $\beta$ in fig. 1. A natural approximation to the solution curve 18 to take $\mu-\frac{1}{2} \beta^{2 / 3}$, drawn as a dashed 11 ne In the figure. Th1s is equivalent to

$$
\lambda_{\mathrm{a}}=\left(\pi / \mathrm{BL}_{\mathrm{o}} \alpha^{2}\right)^{1 / 3}
$$

a mean free path Independent of the Inttlal crack alze, Involving only the number denalty of cracks and the parameter $\alpha$ defining the number of intersectlons that terminates growth. The Jimensionless crack distribution $\tilde{l}+\tilde{m}$ 1s plotted as a function of dimensfonless crack radius in $f(g .2$. 


\section{Prospects for Further Development}

The theoretical work, called statigtical crack mechanica, outlined in this paper is intended for use in finite difference codes. It makes possible the calculation of dynamic problems involving crack growth and coalescence that alise, sypically, in impact and exploston processes. It has been used to Investigate blasting in ofl shale and the sensitivity of propellantg to 1mpact. The approach has been to use analytic solutions to crack problems, to assume the sirplest growth law, which 1nvolves self-simflar growth of penny-shaped cracks, and to consider the statistics of crack coalescence using the simplest Liouvtle equaiton. Thio has made it possible to develop a computing dsheme which works fairly well, though the complexity of the processes involved and uncertainties in the mfcroetructure makes it very difficult to cumpare calculations with experiment. The calculations assume 9 posathle crack orlentatioris, thereby allowing for highly anisotroplc behavior, with crasks in one orientition typically dominating. It is also aysumed that the Initial dfutrtbution of cracks is exponential in crack radius, with different distributions for each orientation being allowed. The strongly anisotroplc behavior of ofl shale resulting from tts sedimentary formition was repregented hy allowting for en extra sei of large cracks in the bedd'ng planes. The number of crack rets (orlentation and size digtrlhution) can be rendily modifted in numerical schemes.

Numerous physlcal effects were lpnored In developing the computat lonal framework, In urder to get " worklny computer code as soon na possible. Thls mnde it posstble to exaint ne many computational problems, Including computer the a:id storape requlrementa, In the courge of code development. It uppears that computing apeed la ahout $n$ thler of that for almple atrength thcorles (rlantlc flow) and the memory requlrement la roughly doubled. Some 
of the studies needed to Improve the existing code are discussed in thi next paragraph.

It would be useful to accour: Eor crack Interactions, which are currently neglrcted, in some approximate way, especially since compression fallures seem to Involve coalescence of riacks into complex patterns. T.t would also be useful to account for out-cif-plane growth of cracks, espec1ally In compression where such effects sesin to be very important. However, the statistical problen is greatly complicated when cracks assume complex shapes, and approximation methods would have to be devised. The effect of varying mean-free-path has heen discussed at length in this paper. It seems probable that means for accounting for this effect within the computer code can be found, but work has not begun on this problem. Ilowever, the method described In the preceding section assumes an lsotroplc distribution. If used In itg current biate, t.t rould be necessary to give up the anisotropy that 1a allowed in the 1inecr, sma1l-growth approximation. We hope to develop an apploximate thenry that comblnes aspects of both approaches. In the orlginal work it was thought feasible to account for plastic behavior in rocks and other materials by autably modifying the rulcs for interfacial friction of closed cracks. Thle effort 18 in $11 \mathrm{mbo}$, and we have tnstead $t$ corporated a phenomenological law (kinematic hardening) to account for plastic flow. Currently, Intorfactal friction is repreaented with a statc value for locked cracks and a dynamic value for gllding cracks. [t has been shown (Dieneg 1983h) that softentng and melting can occur very qufckly on olidtng cracks, and this inay plny an Important role In hiph-gpeed processes. In fact, it may be that shear cracks beinve more 11ke shear bands under anme conditions. A careful trentment of this problem would be of Reent Intereat. Crack apoed la currently treated na a constant (somewhit 
below elastic wave gpeeds) at high stiesses, but decreasing with stress to a high power at stresses below a critical value, in accord with propellant data. Different speeds are assumed for tension and shear cracks. The program also computes permeability, which can be highly anisotroplc, but no allcwance 18 made for crack opening or propagation due to internal gas pressure. Whether this effect is important is en open question 1n rock blast1ng. Another area of concern 1s the effect of Inhomogenities, such as the aggregate in concrete, aluminum in propellarits, or Inclusions 1n rock, whici can profoundly affect crack stability and the pattern of crack growth, but no means for accounting for those effects have ye: been devised.

Thus, with statistical crack mechanf.cs it is pussible to account for fallure In a somewhat detalled way, and the possibility of understanding processes such as fragmentation, spall, explosive and propellant. gensitivity, blasting, ann profectile penetration aie greatly 1mproved. On the other hand, many new questions about fallur, mechanlsms are ralsed. More correlation with expertments and development of suttable diagnostics is needed to test the proposed approach to fallure. On the other hand, it seeme likely that we w11 be able to Improve predictions and interpretations of fallure more reliably with otatistical crack mechanicy and, t.n particular to understand better size and rate effects, which have not been amenable to detalled theoretical analyais in the past. These effecta are now known to be of preat importance, urd better methods to relate laboratory and field behavior IIs well as atutic aid dynamic behavior are needed.

Ackınw i.edgment

I Im lindebted to $R$. M.jolsnusa for golng over the analyals of vartable menn frec path, polnting out an orror, and for useful disciselons. 
APPENDIX A

Consider a space filled with penny-shaped cracks. It is useful to compute the distribution of segments formed by their intersections with a plane, s. If the cracks are randomly, tsotropically, and homogeneously distributed, then the segmei.t distribution is independent of $\mathrm{S}$. Now, let $n(Q, C)$ denote the number of cracks per unit volume and per sterradian with orlentation $Q$ whose radil exceed $c$. Take the plane $S$ as the $x-y$ plane, and let the distance of the center of a crack from the $x-y$ plane be deroted by $z$. Let $\theta$ cenote the angle of the crack normal with the $z$ axis, so that

$$
z=\sqrt{c^{2}-\ell^{2} / 4} \sin \theta
$$

where $\ell$ is the length of the Intercept, as 1 llustrated $\ln \mathrm{flg}$. A. Then, the number of cracks whose radil lie in the range $(c, c+\Delta c)$ having centers in the infinite slab $(z, z+\Delta z)$ is

$$
-\frac{\partial n}{\partial c} \Delta c \Delta z
$$

It follows that the number of intercepts with length exceeding $\ell$ by cracks with orfentation $Q 18$

$$
\tilde{n}(l, l)=-\int_{l / 2}^{\infty} d c \int_{-2(l)}^{z(l)} \frac{\partial n}{\partial c} d \zeta=-2 \int_{l / 2}^{\infty} \sqrt{c^{2}-l^{2} / 4} \frac{\partial n}{\partial c} \theta \ln \theta d c .
$$

The number of Intercepts of all orfentations ts, then, 


$$
P(\ell)=\int_{0}^{\pi / 2} \sin \theta \mathrm{d} \theta \int_{0}^{2 \pi} \tilde{n}(\ell, \Omega) \mathrm{d} \phi
$$

Carrying out the integrations over $\phi$ and $\theta$ on the asaumption of random or1entation one $f$ inds

$$
P(0)=\pi^{2} \int_{0}^{\infty} n d c
$$

The more general case of the relation between $P(l)$ and $n(l)$, which can be reduced to an Abelian Integral. equation, is digcissed by Dienes (1979c), but here only the result given above is necesgary. Since

$$
n=\mathrm{N} / 2 \pi
$$

the number of rack intercepts per unit area an also be written

$$
P(0)=\frac{\pi}{2} \int_{0}^{\infty} i N d c
$$


APPENDIX B

The number of crack Intercepts per untt area with an arbitrary plane S, counting only those cracks that are Inactive, lo given by

$$
\eta_{1}=\frac{\pi}{2} \int_{0}^{\infty} M(c) d c
$$

using the result of Appendix A. This relation can be expressed in terms of the density $L$ in the following manner. Let

$$
m m-M_{c \gamma}-L_{c \gamma}+L_{c c}
$$

denote the rate of production of connected cracks. In $f$ tg. B the $\gamma-c$ plane Is divided Into regions $G$ where growth oscurs and $N G$ where it does not. In G

$$
M=\int_{0}^{\gamma} d \bar{\gamma} \int_{0}^{\infty} m d \bar{c}
$$

and in NG

$$
M=\int_{0}^{c} d \bar{\gamma} \int_{c}^{\infty} m d \bar{c}+\int_{c}^{\gamma} d \bar{\gamma} \frac{\int_{\gamma}^{\infty} m d \bar{c} .}{\gamma}
$$

Thea, 1t is atralghiforward to show that in $G(\gamma<c)$

$$
M=L_{(0, r)}-L_{1}(\gamma, c)-\int_{0}^{\gamma} I_{r}(\bar{\gamma}, r) d \bar{\gamma}
$$

and In NG: $(\gamma>c)$ 
26

$$
M=L(0, c)-L(\gamma, \gamma)-\int_{0}^{c} L_{c}(\bar{\gamma}, c) d \bar{\gamma} \text {. }
$$

Using these results to evaluate (B1) it can be shown that

$$
\eta_{1}=\frac{\pi}{2}\left\{\int_{0}^{\infty} L(0, c) d c-\int_{\gamma}^{\infty} L(\gamma, c) d c+\int_{0}^{\gamma} L(c, c) d c-\gamma L(\gamma, \gamma)\right\} .
$$

(B7) 
Dienes, J. K. (1978), "A Statistical Theory of Fragmentation", In: Y. S. K1m, ed. Proc. 19th U.S. Rock Mechanics Symposium, Stateline, Nev.

Dienes, J. K. (1979a), On the Analysis of Rotation and Stress Rate in Deforming Bodies", Acta Mechanica, 32, 217.

Dienes, J. K. (1979b), "Theory of Explosions In Anistotrop1c Media", In: J.P. Boehler ed., Mechanical Behavior of Anleotroplc Sollds, Proc. Eiromech Colloquium 115, Villard-de-Lans, France.

Dienes, J. K. (1979c), "On the Inference of Crack Statistics from Observations on an Outcropping", In Proc. 20th U.S. Sympos 1um on Rock Mechan1cs, Austin, TX.

Dienes, J. K. and L. G. Margolin (1980), "A Computational Approach to Rock Fragmentation", In: D. A. Summera, ed., The State of the Art in Rock Mechanics, Proc. 21 te U.S. National Symposium on Rock Mechanice, Rolla, Mo.

Dienes, J. K. (1981), "On the Effect of Anisotropy in Explogive Frugmentat1on", 1n: H. H. E1ngtein, fd., Rock Mechanics from Research to Application, Proc. 22nd U.S. Symposium on Rock Mechan1c8, Massachusetts Institute of Technology.

Dienes, J. K. (1982), "Permeability, Percolation and Statistical Crack Mechanics", In: R. E. Goodman and F. E. Heuze, eds., Issues In Kock Mechanics, Pruc. 23rd Symposium on Rock Mechanics, Berkeley, CA.

Dienes, J. K. (1983a), "Statiotical Crack Mechanics", In: J.-P. Huehler, ed., Fallure Criteria of Structured Media, proc. Colloque Internntional du CNRS no. 351, V1llard-de-Lang, France.

Dienes, J. K. (1983h), "(On the Stabtl1ty of Shenr Cracks and the culculation of Compress1ve Strength", J. Ceophys. Rey., HB, 1173.

Dienes, J. K. (1984A), "The liffect of Fiulte Rutation on a Problem Ln Plastlc Deformation", In $\Lambda$. S. Khan, Lid., Bell Anulversary Volume, Proc. Int'1 Sympan 1 um on Platelclty, Normun, OK.

Dtencs, J. K. (19B4b), "Practure, Falluie, and Frasmentatlon," lin: A. K. Noor, ed., Proce. Sympess lum on Advances and Trends In structures and Dynamleg, Washlugton, I..C.

Keer, L. M. (1966), "A Note on Shear and Cumblined lobadluy for n Ponny-shaped Crack", I. Micch. Mhys. Sollila 14, I

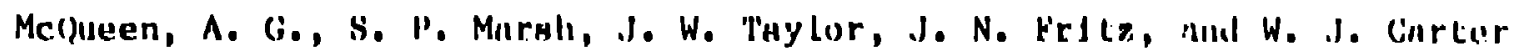

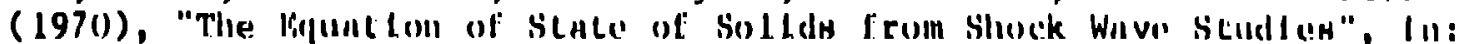

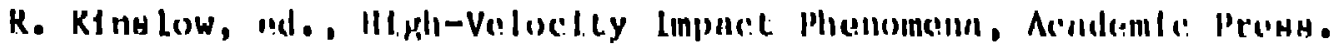

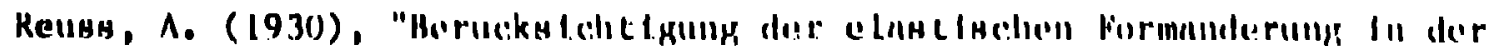

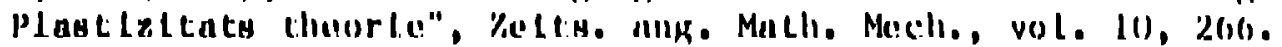


Rice, J. R. (1984), "Comments on 'The Stab1lity of Shear Cracks and the Calculation of Compressive Strength'", J. Geophys. Res., 89, 2415.

Sack, R. A. (1946), "Extension of Griffith's Theory of Rupture to Three Dimenslone", Proc. Phys. Soc. ㅌ, 729.

Segedin, C. M. (1950), "Note on a Penny-Shaped Crack under Shear", Proc. Camb. Ph11. Soc. 47. 396.

Stroh, A. N. (1957), "A Theory of the Fracture of Meta1s", In Advances in Fuysics, Vol. VI. 
F1g. 1. The dimensionless mean free path $\mu=\pi^{2} L_{0} \lambda$ as a function of $\beta=\pi k c^{-3} L_{o} / 2$, In the 11mit of large crack growth $\gamma$. Th1s 11mit depends only on $\beta$, which can be considered a dimensionless crack density. The approximation $u=\frac{1}{2} \beta^{2 / 3}$ may be useful in formulating algorithms for computer analysla.

F1g. 2. The dimenstonless crack distribution function $\tilde{n} n \tilde{l}+\tilde{m}$ as a function of dimensionless crack $81 z e, \theta-c / \bar{c}$, for various values of the dimenstonless parameter $\beta=\pi \mathrm{kc}^{-3} \mathrm{~L}_{\mathrm{o}} / 2$. This distribution $1 \mathrm{~s}$ the $11 \mathrm{mlt}$ at late times, large $\gamma$.

F1g. A. Intersection of a circular crack of radius $c$ with the $x-y$ phase as viewed hortzontally from the edge (leit) and froin a direction at $90^{\circ}$ to the edge ( $r$ gaht). The figure lllustrates the intercepta length $l$, the Inclination $\theta$, and is the basis for Eq. Al.

F1g. B. Illustration of the $\gamma-c$ phase showing reglons where crack growth 1s poseible $(c>\gamma$ ) and imposelble $(\gamma>c)$, for use in computing B3 and 34 . 


$$
\square
$$




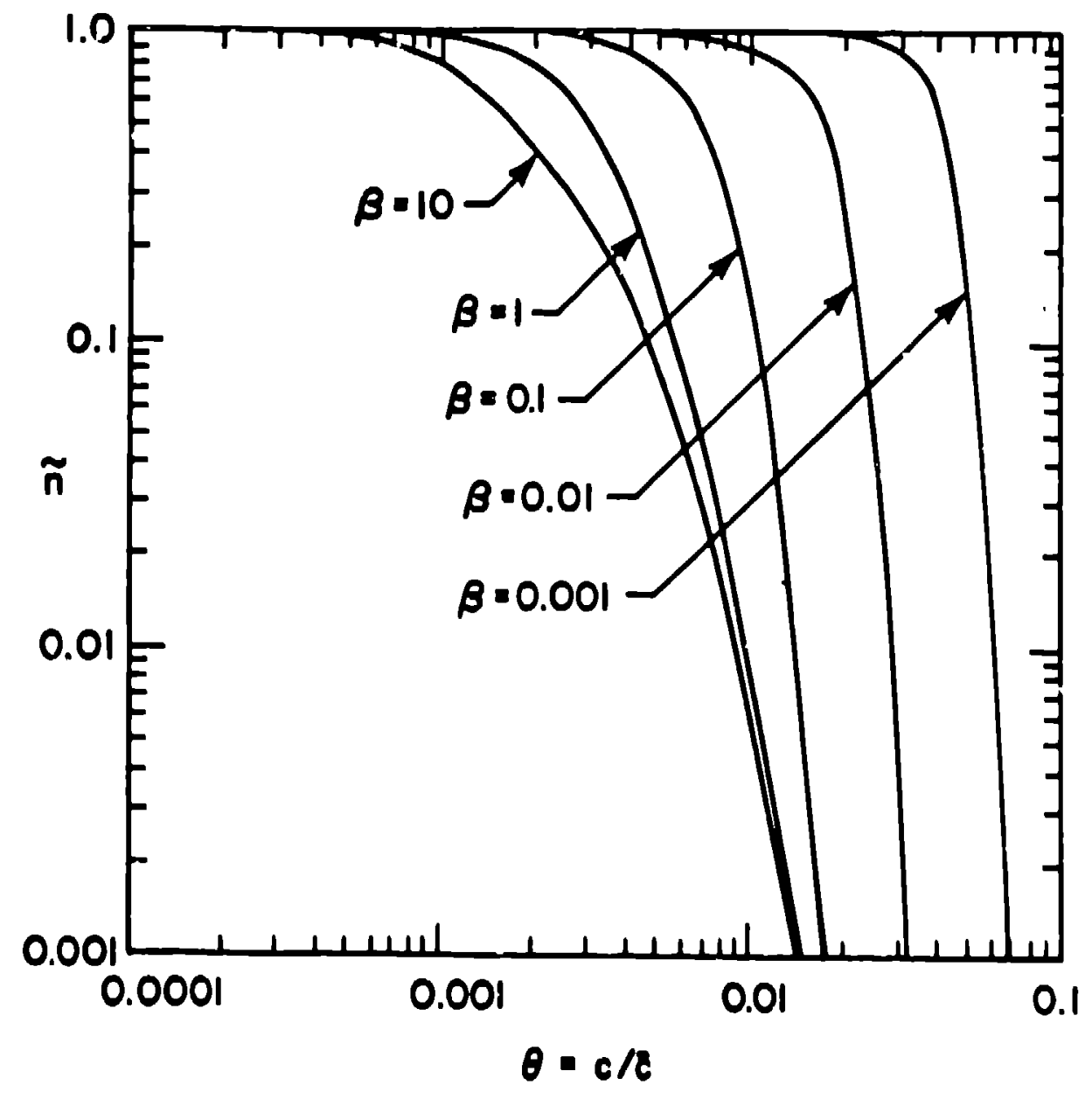

FIg. 2 


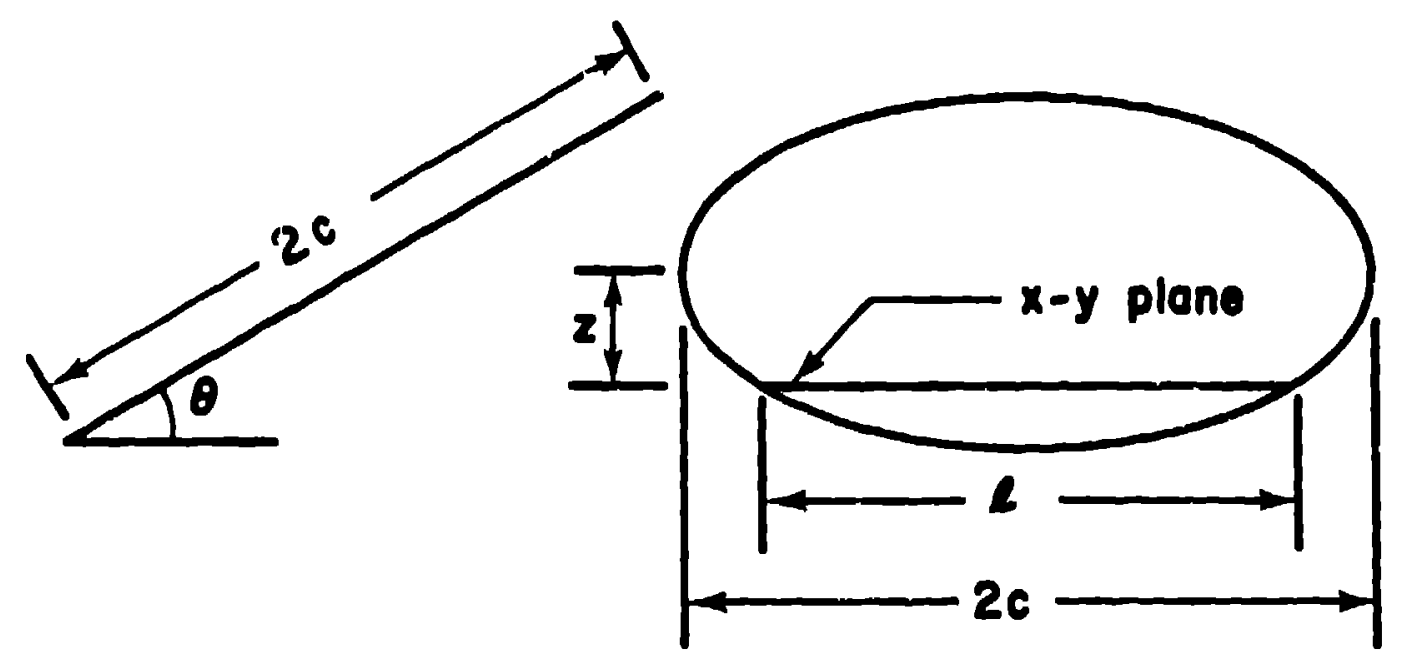

Fig. A 


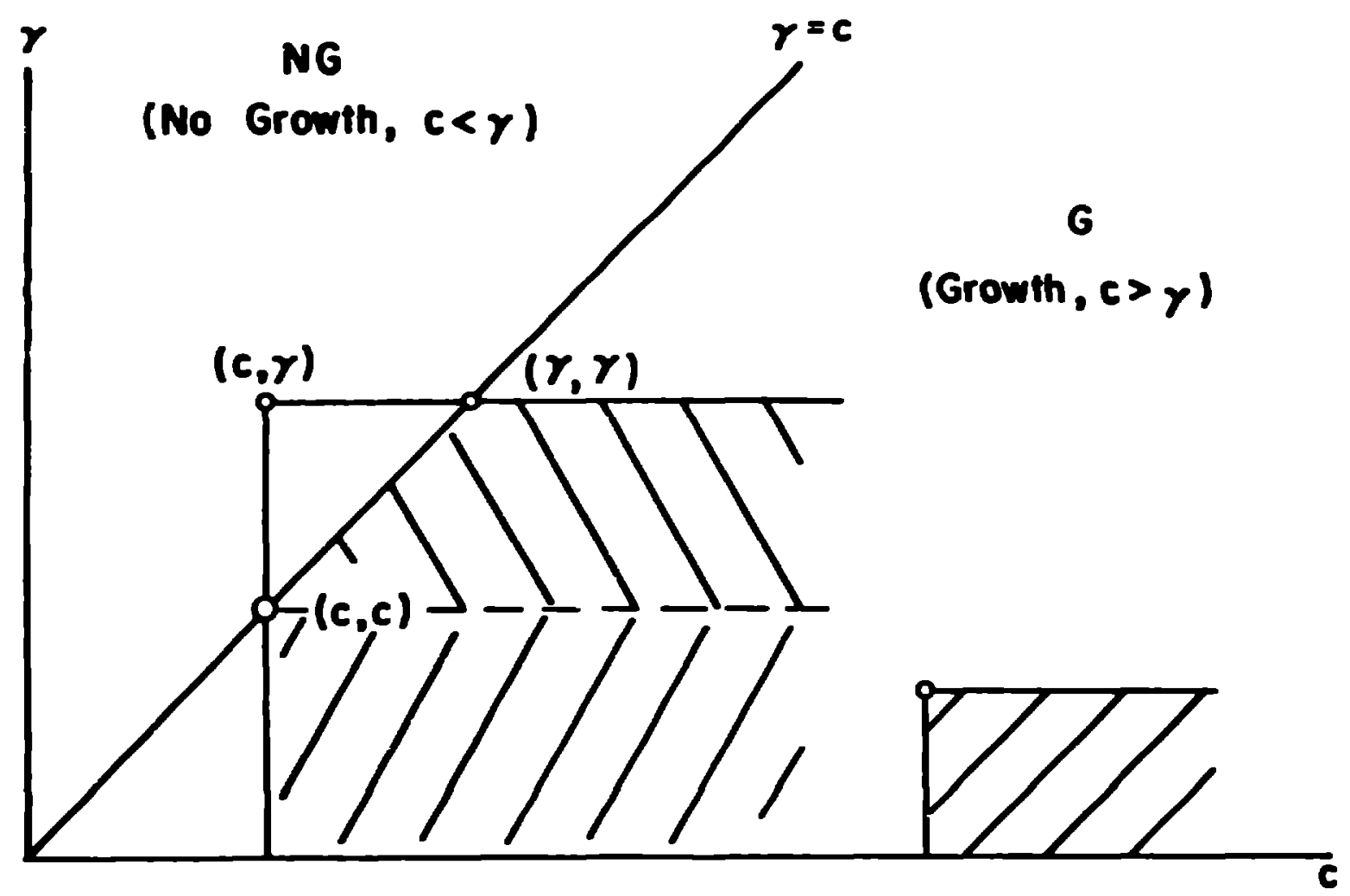

Fig. B 